Canadian Journal of Higher Education Revue canadienne d'enseignement supérieur

Volume 47, No. 1, 2017, pages 114 - 136

\title{
Correlates of Depression in First-Year College Students
}

\author{
Aude Villatte \\ Université du Québec en Outaouais \\ Diane Marcotte \\ Université du Québec à Montréal
}

Alexandra Potvin

Cégep de Saint Jérôme

\begin{abstract}
This study aimed to identify and rank the personal, family-related, social, and academic correlates of depressive symptoms in first-year college students. A questionnaire that included the Beck Depression Inventory-II (BDI-II) was administered to 389 first-year college students (mean age $=18.9 ; S D=3.38$; $59.4 \%$ female). Eight variables contributed uniquely to the variance of depressive symptoms and were, in decreasing order of importance: (1) the absence of personal goals, (2) a high level of anxiety and (3) of dysfunctional thoughts regarding success, (4) a lack of emotional adjustment to college, (5) being female, (6) receiving little warmth and encouragement of autonomy from one's mother and (7) from one's father, and (8) being attracted to members of the same or both sexes. These results suggest that a multimodal intervention is required to support students' mental health.
\end{abstract}

\section{Résumé}

Cetteétudevisaitàidentifier et à hiérarchiser les corrélats personnels, familiaux, sociaux et académiques des symptômes de dépression chez des élèves en première année d'études collégiales. Ainsi, 389 étudiants inscrits en première année d'études collégiales (âge moyen : 18,9 ans; écart-type : 3,38 ans; 59,4 \% de jeunes femmes) ont rempli un questionnaire comprenant l'Inventaire de 
dépression de BeckII. Huit facteurs ont contribué de façon unique à la variance des symptômes de dépression et sont, par ordre décroissant d’importance : (1) l'absence d'objectifs personnels, (2) un niveau d'anxiété élevé, (3) des pensées dysfonctionnelles à propos de la réussite, (4) un faible niveau d'adaptation émotionnelle au Cégep, (5) le fait d'être une femme, (6) le fait de recevoir peu d'affection et d'encouragement vers l'autonomie de la part de sa mère et (7) de son père, et (8) le fait être être attiré par des personnes de même sexe ou des deux sexes. Ces résultats semblent indiquer qu'une intervention multimodale est requise pour soutenir la santé mentale des élèves.

\section{Introduction}

Multiple studies have confirmed a marked increase over the past few years in the number of postsecondary students suffering from mental health problems (Daddona, 2011; Fier \& Brzezinski, 2010; MacKean, 2011). Both teachers and school psychologists are highly concerned about this increase: not only does it reveal the need for more resources; it also calls for a change in orientation with regard to the kinds of services to offer their clientele. There needs to be a move from a preventative and developmental approach toward a more clinical or crisis intervention approach (Kitzrow, 2003).

Depression is one of the most common diagnoses made by mental health professionals dealing with postsecondary students (Marcotte, 2013). In Canada, 44.4\% of postsecondary students surveyed between 2012 and 2014, said that they felt so depressed that it was difficult to function, and $13.0 \%$ reported that they had seriously considered suicide at some point within the previous 12 months (American College Health Association, 2016). A Canada-wide prevalence survey conducted by the Canadian Mental Health Association in 2004 had similar findings, using different data collection instruments. About one third (29.2\%) of undergraduates reported four or more symptoms indicative of elevated distress as measured by the 12-item mental health screen in the General Health Questionnaire. The most common symptoms of distress were as follows: for $47 \%$ of subjects, feeling constantly under strain; for $32 \%$, losing sleep over worry; and for $31 \%$, feeling unhappy or depressed (Adlaf, Demers, \& Gliksman, 2005, cited by MacKean, 2011). A meta-analysis of 34 international articles measuring the prevalence of depression in postsecondary students between 1990 and 2010 shows an average prevalence of $30.6 \%$ with a variance from $10 \%$ to $85 \%$, depending on the measurement criteria, geographic origin, and characteristics (especially socioeconomic) of the sample (Ibrahim, Kelly, Adams, \& Glazebrook, 2013). This rate exceeds the approximately $10 \%$ prevalence typically observed in samples of nonstudent emerging adults (Gonzalez et al., 2010; Ibrahim, Kelly, \& Glazebrook, 2012). The pressure to succeed, questions regarding employment prospects, as well as the cost of education, may help to explain these particularly elevated rates (Beiter et al., 2015).

Considering the extremely costly personal and social repercussions of these difficulties, including substance abuse, college dropout, suicide, and health care costs (Imhasly, 2008; Jeon, 2011), identifying depression risk factors in postsecondary students is essential. The results may help to open avenues for the creation of prevention and treatment programs for students who are vulnerable to depression, and for whom and too few resources have been available within postsecondary institutions, although this situation is changing (Storrie, Ahern, \& Tuckett, 2010). 


\section{Correlates of Depressive Symptoms during the Transition to Adulthood}

Although the developmental period of emerging adulthood is subject to an increase in depression disorders, the associated risk factors remain less known than those of adolescents (Ibrahim et al., 2013).

Family-related correlates. According to the literature (Gourion et al., 2008; Smith \& Blackwood, 2004), the presence of a depressed parent is one of the principal risk factors for depressive symptoms in emerging adulthood, especially for female subjects (Morris, McGrath, Goldman, \& Rottenberg, 2014). This influence has been found from both biological and adoptive parents (Marmorstein, Iacono, \& McGue, 2012). Furthermore, coming from a dysfunctional, violent, or neglectful family (Fletcher, 2009), the absence of emotional support (Needham, 2008; Wickrama, Wickrama, \& Lott, 2009) and encouragement of autonomy (Kins, Soenens, \& Beyers, 2012), and being in conflict with one's parents (Galambos, Barker, \& Krahn, 2006) are also linked to the presence of depressive symptoms in emerging young adults.

With regard to the influence of sociodemographic family-related factors, the results are more contradictory. Indeed, while some authors have emphasized that the level of depressive symptoms in emerging adulthood is linked to the parents' socioeconomic and sociocultural level (Gore \& Aseltine, 2003; Kim, Han, Hill, Rose, \& Roary, 2003), and especially to the mother's education level (Park, Fuhrer, \& Quesnel-Vallée, 2013), others have shown that it is neither a risk factor nor a protective factor (Duncan \& Rees, 2005; Pelkonen, Marttunen, \& Aro, 2003; Reinherz, Giacona, Carmola Hauf, Wasserman, \& Silverman, 1999).

Personal correlates. For the most part, there is agreement among authors that female adolescents are more than twice as likely as their male counterparts to suffer from depressive symptoms (Ghodasara, Davidson, Reich, Savoie, \& Rodgers, 2011; Marcotte, 2013; Richards \& Salamanca Sanabria, 2014). However, recent studies were not able to replicate these results among college samples (Ibrahim et al., 2012, 2013). Low self-esteem (Eisenbarth, 2012; Pelkonen et al., 2003; Pelkonen, Marttunen, Kaprio, Huurre, \& Aro, 2008), the presence of cognitive distortions regarding one's self, the outside world, and the future (Alloy et al., 2006; Peden, Rayens, Hall, \& Beebe, 2001; Pirbaglou et al., 2013), as well as the presence of anxious symptoms also contribute to the presence of depressive symptoms in emerging adulthood. Having previously experienced a depressive episode (Frye \& Liem, 2011; O'Hara, Armeli, Boynton, \& Tennen, 2014; Pelkonen et al., 2008) and having had negative life experiences, such as moving or being in a car accident (Hazel, Hammen, Brennan, \& Najman, 2008), also have an impact on the development of depressive symptoms in emerging adulthood. Moreover, multiple studies emphasize that problematic substance use and dependencies (Fergusson, Boden, \& Horwood, 2009; Geisner, Mallett, \& Kilmer, 2012), including Internet overuse (Koc, 2011; Locatelli, Kluwe, \& Bryant, 2012), increase the risk of developing major depressive disorders.

Social correlates. A lack of social support from peers during adolescence represents a risk factor in depressive symptoms during adolescence and emerging adulthood (Gore \& Aseltine, 2003; Pettit, Roberts, Lewinsohn, Seeley, \& Yaroslavsky, 2011). According to some studies, this effect is especially significant among female youth (Choi, Patten, Christian Gillin, Kaplan, \& Pierce, 1997), while other studies have found a significant dif- 
ference only among male youth (Pelkonen et al., 2003). While some authors emphasize that social support from peers does more to explain the level of depressive symptoms during adolescence and emerging adulthood than does social support from parents and teachers (Reinherz et al., 1999; Young, Berenson, Cohen, \& Garcia, 2005), others have found that peer support is not more important than family support (Eberhart \& Hammen, 2006; Galambos, Leadbeater, \& Barker, 2004; Pettit et al., 2011).

Results linking romantic relationships and depressive symptoms are very rare and relatively difficult to interpret. While some authors have not identified an impact of romantic status (Rosal et al., 1997) or romantic dissatisfaction (Rizzo, Daley, \& Gunderson, 2006) on depressive symptoms in emerging adulthood, others have shown a negative link between being in a relationship (Whitton, Weitbrecht, Kuryluk, \& Bruner, 2013) or being satisfied in the relationship (Whitton \& Kuryluk, 2012) and symptoms of depression in young female adults.

Associations have been identified between depressive symptoms in emerging adulthood and other social risk factors, such as social exclusion stemming from discrimination linked to ethnicity, gender, physical disability, sexual orientation, immigrant status, or religion (Grant et al., 2013; Kerr, Santurri, \& Peters, 2013; Miranda, Polanco-Roman, Tsypes, \& Valderrama, 2013; Wichstrøm \& Hegna, 2003).

Academic correlates. Within the student population, certain subgroups are particularly at risk of experiencing depressive symptoms. This is especially the case for students in specific programs such as medicine, psychology, and social work (Bouteyre, Maurel, \& Bernaud, 2007; Rosenthal \& Wilson, 2008) as well as for students having just completed the transition from secondary to postsecondary education (Boujut, Koleck, BruchonSchweitzer, \& Bourgeois, 2009). The transition to the postsecondary level can be a highly stressful period for emerging adults, as they experience a double transition that is both developmental and institutional (Mackinnon, Sherry, Pratt, \& Smith, 2014; Marcotte, 2013). Indeed, nearly 50\% of students struggling with a mental disorder say that their symptoms began at the same time as their postsecondary studies (Benton, Robertson, Tseng, Newton, \& Benton, 2003). These new students face a variety of potentially stressful elements, including increased freedom, a heavier workload outside of class, heightened academic expectations, and the need to determine their vocational choice (Schwartz, Côté, \& Arnett, 2005).

A range of factors linked to the academic sphere can also be associated with a risk of depressive symptoms in emerging adulthood. Weak academic results are associated with the presence of depressive symptoms in postsecondary students, especially in female ones (Pelkonen et al., 2003, 2008; Reinherz et al., 1999). Having been the victim or perpetrator of bullying in a school setting during adolescence is also thought to be linked to a higher level of depressive symptoms in emerging adulthood (Lencl \& Matuga, 2010).

Combination of risk factors. It appears, then, that a great number of variables or correlates are linked to the presence of depressive symptoms in emerging adulthood and, more specifically, in postsecondary students. While acknowledging the multifactorial etiology of depression, the research has focused very little on the combination of these different kinds of correlates. By following a sample of 507 North American students between the ages of 17 and 31 over four years, Klein et al. (2013) attempted to isolate the predictive factors of a first major depressive episode occurring during emerging adulthood. To do this, the researchers used 20 sociodemographic, personal, family-related, and social vari- 
ables. Female gender, a family history of mood disorders, a history of childhood sexual abuse, a history of anxiety disorder before age 18, poor self-reported physical health, and subthreshold depressive symptoms were statistically significant after correction for multiple comparisons. Their study demonstrated the value of considering a combination of multiple risk factors, even though academic factors were not included. These results are limited, however, to explaining the occurrence of a first depressive episode in emerging adulthood, instead of the presence of depressive symptoms in students enrolled in their first year of postsecondary studies.

Current study. In line with this research, the present study sought first to identify the correlates of depressive symptoms in first-year college students and then to develop a hierarchy of these correlates. It was hypothesized that the presence of depressive symptoms in these students is the result of a simultaneous combination of multiple risk factors, whether sociodemographic, personal, family-related, or academic.

\section{Methods}

\section{Procedure}

At the end of the summer of 2012, a college of 1160 students in a southern suburb of Montreal, Quebec, was approached to participate in this study. A professional contact person was identified within the college to ensure communication with the research team.

Through October and November 2012, research assistants experienced in administering questionnaires met with 20 classes of students enrolled in their first year of study at the college. Special efforts were made to contact students from all the programs offered at this institution. At the start of the meeting, the assistants introduced the project and the ethical issues related to participation in the study. Students willing to complete the questionnaires were then asked to sign a consent form. After giving their free and informed consent and signing the form, the participants were presented with the protocol (several questionnaires compiled in a booklet to be completed manually). The questionnaires were administered in class in the presence of the teacher or the research assistant. On average, it took 35 to 40 minutes to complete the questionnaire. Students who were absent when the questionnaires were administered were contacted by email and met during class hours. This was done so as not to lose sight of those who could potentially be at risk for depressive symptoms. In all, 393 students (more than 95\% of the sample contacted initially) participated in the data collection. Four questionnaires completed by participants aged 36 years or more were deleted so as to limit the heterogeneity of the sample.

\section{Participants}

The sample, which included more female ( $n=231$ or $59.4 \%)$ than male subjects ( $n=158$ or $40.6 \%$ ), was made up of 389 first-year college students between the ages of 16 and 35 (mean age $=18.9 ; S D=3.38$ ), of whom $96 \%$ were White. Nearly all of them were full-time students (97.9\% compared with $2.1 \%$ part-time students). About two thirds (68.8\%) of the students in the sample were employed alongside their studies. They worked an average of 10.59 hours $(S D=9.28)$ per week, with nearly $21 \%$ working more than 17 hours per week. Of the sample, 60.9\% lived in a traditional-style family (two parents living together), $22.7 \%$ lived with one parent or in a blended family, and $16.4 \%$ no longer 
lived with their parents. While $36.2 \%$ of the participants said that their father's education was equivalent to a secondary-school level, 33.7\% said that their mother's education was equivalent to a college level. A small proportion of the participants said that their mother (5.1\%) and their father (7.5\%) had a primary-school level of education. Whereas $11.5 \%$ of participants said they did not know their parents' combined income, $19.8 \%$ believed it to be less than $\$ 44,999 ; 15.2 \%$ believed it ranged from $\$ 45,000$ to $\$ 59,999 ;$ and $14.7 \%$ thought it ranged from $\$ 60,000$ to $\$ 74,999$. Of the sample, $38.8 \%$ thought their parents' combined income was $\$ 75,000$ per year or more. (All values in Canadian dollars.)

\section{Measures}

In an effort to reveal the multiple factors capable of influencing depressive symptoms in college students, multiple measures-linked to personal, family-related, academic, and social areas-were selected. The complete set of measures was compiled in self-reported questionnaires.

Depressive symptoms. The Beck-II Depression Inventory (BDI-II; Beck, Steer, \& Brown, 1996) was used to detect students with depressive symptoms. This instrument contains 21 statements that measure the severity and variation of depressive symptoms over the preceding two weeks. Participants are asked to choose, from among four statements, the one that best matches their current state. Four levels of depressive symptoms can then be identified, as established by Beck et al. (1996): absence (total score between 0 and 11), mild (score between 12 and 19), moderate (score between 20 and 27), or severe (score of 28 and above). In the present sample, a good internal consistency coefficient was obtained (Cronbach's alpha: $\alpha=.889$ ).

Sociodemographic characteristics. Using the descriptive questionnaire, the students were asked to give their gender, age, study program, academic status (full-time or part-time studies), and work situation (hours per week spent working). Also collected was information on the students' family makeup (e.g., blended or traditional family), their mother's and father's sociocultural level (financial income and education level), as well as the students' romantic status (in a relationship or single).

Family dynamics. The Family Environment Scale (Moos \& Moos, 1994) includes 45 items separated into five subscales: cohesion, expressiveness, conflict, organization, and control. For this study, we retained only three items related to the "conflict" dimension and two items from the "cohesion" dimension. The participants were asked to position themselves with regard to these dimensions on a 5-point Likert scale. Within the cohesion dimension, we added a third item from the National Longitudinal Survey of Children and Youth (Statistics Canada, 2008): "In our family, we very often eat meals together." Both scales had satisfactory internal consistency in the present sample: Cronbach's $\alpha=.704$ and .749 , respectively.

The scale of parental expectations (Robbins, 1994) measured the extent to which parents provided an ideal parental context. The version aimed at college or university students evaluated how these young people perceived the warmth and encouragement of autonomy provided to them by, on the one hand, their father and, on the other hand, their mother. The original questionnaire included 42 items presented in the form of 6-point Likert scales. Only 30 items were retained: the same 15 for both the mother and the father (Cronbach's $\alpha=.859$ and $\alpha=.833$, respectively). 
Finally, based on nine items, the Parental Supervision Questionnaire (Kerr \& Stattin, 2000) measured how students evaluated their parents' knowledge of their outings, friends, and studies. For each of these items, participants were asked to position themselves on a scale of 1 to 5 (Cronbach's $\alpha=.909$ ).

Support from friends. The Perceived Social Support from Friends measure (PSSFr; Procidano \& Heller, 1983) evaluates how the needs for support, information, and feedback are met by friends. In the present study, an abridged and adapted version of the instrument contained five items rated on a 6-point Likert scale (Cronbach's $\alpha=.814$ ).

Romantic relationship quality. Romantic relationship quality was measured using the Network of Relationships Inventory (Buhrmester \& Furman, 1987). In the context of this study, the only scales (5-point Likert) retained were those that measured the participants' evaluation of their satisfaction, intimacy, and the level of conflict regarding the romantic relationship (satisfactory Cronbach's alphas of .934, .832, and .865, respectively).

Sexual orientation. One item was used to define the participants' sexual orientation: "With regard to my attraction and my sexual preferences, I am: always attracted to a woman/always attracted to a man/more often attracted to a woman/more often attracted to a man/attracted to a woman as often as I am attracted to a man" (Otis, Ryan, \& Chouinard, 1999).

College adjustment. The original self-report questionnaire regarding students' adjustment to college (the French translation of the Student Adaptation to College Questionnaire, or SACQ; Baker \& Siryk, 1986) comprises 67 items for which the participants indicate their degree of agreement on a 9-point Likert scale. Two items measure general adjustment (e.g., "I believe I'm dealing well with my situation at college"), while others deal with more precise facets (or subscales) of this adjustment: academic adjustment, personal-emotional adjustment, attachment to the college institution, and social adjustment. In the context of this research, only 22 items stemming from these four major dimensions were retained. This questionnaire needed to be modified due to its unsatisfactory internal consistency (Cronbach's $\alpha$ less than .60) on each of the scales. Based on a principal components analysis (PCA) with orthogonal varimax rotation carried out on our sample data, the Statistical Package for the Social Sciences software, or SPSS, indicated the presence of four empirically independent factors explaining $54.2 \%$ of the total variance. The Kaiser-Meyer-Olkin index (.771) and Bartlett test of sphericity (<.001) demonstrated the importance of conducting this factor analysis. For each factor that was revealed, items presenting a correlation index greater than .400 for one single factor were retained. One of the 22 initial items was deleted ("I'm very involved in college social activities"), as it did not exhibit any factor loading greater than .400 . The remaining 21 items were divided into the following factors: academic motivation (Cronbach's $\alpha=.753$ ), attachment to college (Cronbach's $\alpha=.780$ ), academic adjustment (Cronbach's $\alpha=.620$ ), and emotional adjustment to college (Cronbach's $\alpha=.697$ ).

Academic performance. Two questions measured the participants' rating of their academic performance (below average, average, above average).

Anxiety. The French-language version (Freeston et al., 1994) of the Beck Anxiety Inventory (BAI; Beck, Epstein, Brown, \& Steer, 1988) measured the general somatic symptoms of anxiety experienced by the participants over the preceding week. This tool comprises 21 items measured on a scale of o to 3 (Cronbach's $\alpha=.889$ ). 
Cognitive distortions. Cognitive distortions related to internalized disorders were measured using the short version (validated by Marcotte, Marcotte, \& Bouffard, 2002) of the Dysfunctional Attitudes Scale (Power et al., 1994). Eight items were retained (four for the scale related to dysfunctional thoughts concerning success, four for the scale related to cognitive distortions linked to dependence), for which the participants had to position themselves on a 7-point scale. Cronbach's alphas were satisfactory for each of these scales (.635 and .641, respectively).

Deviant behaviour. In this study, the self-reported Delinquency Questionnaire (LeBlanc, 1994), originally made up of 26 items, was reduced to five items so as to measure-using 4-point Likert scales-the frequency of violent behaviour (three items) and substance abuse (alcohol and drugs, two items) over the course of the preceding 12 months (Cronbach's $\alpha=.657$ ).

Personal goals. Personal goals were measured using the Goal Instability Scale (Robbins, Payne, \& Chartrand, 1990). This questionnaire comprises 10 items (Cronbach's $\alpha=.881$ ), such as "I don't know where I'm going anymore," for which participants had to position themselves along a 6-point Likert scale.

Professional goals. With regard to the participants' professional life, the Vocational Identity Scale was used (Holland, Gottfredson, \& Power, 1980). This scale comprises 10 items, each of which offers a statement (e.g., "I'm not sure that my current choice of profession is right for me") for which the participants had to indicate their level of agreement on a 5-point scale. For this study, only six of these items were retained (Cronbach's $\alpha=.869$ ).

\section{Results}

Within the sample, the average depressive symptoms score was $10.76(S D=8.29)$. According to the clinical thresholds of the BDI-II, $59.6 \%$ of the participants $(n=232)$ had no depressive symptoms (score between o and 11), 27.0\% $(n=105)$ had mild depressive symptoms (score between 12 and 19), 9.3\% $(n=36)$ had moderate depressive symptoms (score between 20 and 27), and 4.1\% $(n=16)$ had severe depressive symptoms (score greater than or equal to 28). Considering the thresholds retained by Beck et al. (1996), $59.6 \%$ of the study participants could therefore be considered "not depressed," while $13.4 \%$ could be considered "depressed" (score of 20 or more).

\section{Preliminary Analysis}

To identify the sociodemographic, family-related, personal, social, and academic variables linked to depressive symptoms, the various independent variables were tested separately. One-way ANOVAs were used for nominal or ordinal variables, while Pearson's correlation coefficients were used for continuous variables.

Table 1 shows the results used to identify the links between depressive symptoms and sociodemographic variables. Of the entire sample, female students were significantly more depressed than their male peers. Furthermore, the older the students, the more they showed signs of depression. The other sociodemographic variables (e.g., being a "new student" or not, being enrolled in a pre-university or technical study program, having more or less educated parents) were not significantly linked to depressive symptoms. 
Table 1.

Associations (Fisher's F and Pearson's r) between Sociodemographic Variables and Depression Score

\begin{tabular}{|c|c|c|c|c|}
\hline Variable & & Mean $(S D)$ & Fisher's $F(\mathrm{ddl})$ & Pearson's $r$ \\
\hline \multirow[t]{2}{*}{ Gender } & Male & $8.82(7.45)$ & \multirow{2}{*}{$F_{1,387}=15.094^{* * *}$} & \multirow{2}{*}{ NA } \\
\hline & Female & $12.09(8.59)$ & & \\
\hline Age & NA & NA & NA & $-.112^{*}$ \\
\hline \multirow[t]{2}{*}{ Academic status } & New student & $11.29(8.20)$ & \multirow{2}{*}{$F_{1,387}=0.005$} & \multirow{2}{*}{ NA } \\
\hline & Returning student & $11.21(9.83)$ & & \\
\hline \multirow[t]{2}{*}{ Study program } & Pre-university & $11.17(8.14)$ & \multirow{2}{*}{$F_{1,387}=1.390$} & \multirow{2}{*}{ NA } \\
\hline & Technical & $10.19(8.21)$ & & \\
\hline \multirow[t]{2}{*}{ Living situation } & With family & 11.26 (8.99) & \multirow{2}{*}{$F_{1,384}=1.591$} & \multirow{2}{*}{ NA } \\
\hline & Without family & $8.24(7.18)$ & & \\
\hline $\begin{array}{l}\text { Hours of employ- } \\
\text { ment per week }\end{array}$ & NA & NA & NA & .061 \\
\hline \multirow{3}{*}{$\begin{array}{l}\text { Education level } \\
\text { Mother }\end{array}$} & Primary & $11.40(8.95)$ & \multirow{3}{*}{$F_{3,384}=0.562$} & \multirow{3}{*}{ NA } \\
\hline & Secondary & $10.14(9.18)$ & & \\
\hline & Postsecondary & $21.91(15.56)$ & & \\
\hline \multirow[t]{3}{*}{ Father } & Primary & $10.03(7.23)$ & \multirow{3}{*}{$F_{3,384}=0.163$} & \multirow{3}{*}{ NA } \\
\hline & Secondary & $11.08(9.07)$ & & \\
\hline & Postsecondary & $21.17(14.61)$ & & \\
\hline \multirow[t]{3}{*}{$\begin{array}{l}\text { Parental income/ } \\
\text { year }\end{array}$} & $\leq \$ 44,999$ & $9.45(5.89)$ & \multirow[t]{3}{*}{$F_{2,385}=0.965$} & \multirow[t]{3}{*}{ NA } \\
\hline & $\$ 45,000-74,999$ & $10.70(8.66)$ & & \\
\hline & $\geq \$ 75,000$ & $9.60(7.54)$ & & \\
\hline
\end{tabular}

Note Mean = mean depression score; $S D=$ standard deviation; ddl = degrees of freedom; NA = not applicable.

${ }^{*} p<.05 .{ }^{* *} p<.01 .{ }^{* * *} p<.001$.

All variables related to family functioning were significantly associated with depressive symptoms (Table 2). The more positively the students perceived their family functioning (absence of conflict and strong cohesion), the more they felt both their father and their mother encouraged their autonomy while showing them affection, and the more they felt their parents had a general idea of their activities and of the people they spent time with, the less they showed signs of depression.

Several of the personal variables measured were significantly associated with depressive symptoms (Table 3). The more the students had dysfunctional thoughts concerning success ("If I don't completely succeed, it's like failing") and dependency ("I must please everyone"), the more anxious they were; and the less they had clearly defined professional and personal goals, the more they experienced symptoms of depression. However, deviant behaviours (violence and substance abuse) were not correlated with depressive symptoms. 
Table 2.

Correlations (Pearson's r) between Family-Related Variables and Depression Score

\begin{tabular}{llc}
\hline Variable & \multicolumn{1}{c}{ Modality } & Pearson's $r$ \\
\hline Family functioning & Total score & $-.360^{* * *}$ \\
& Cohesion & $-.289^{* * * *}$ \\
Encouragement of autonomy-mother & Absence of conflict & $-.337^{* * *}$ \\
Encouragement of autonomy-father & & $-.346^{* * *}$ \\
Warmth-mother & & $-.340^{* * *}$ \\
Warmth-father & $-.393^{* * *}$ \\
Parental supervision & $-.419^{* * *}$ \\
\hline
\end{tabular}

${ }^{*} p<.05 .{ }^{* *} p<.01 .{ }^{* * *} p<.001$.

Table 3.

Associations (Fisher's F and Pearson's r) between Personal Variables and Depression Score

\begin{tabular}{llc}
\hline Variable & \multicolumn{1}{c}{ Modality } & Pearson's $r$ \\
\hline Dysfunctional thoughts & Total score & $.429^{* * *}$ \\
& Success & $.359^{* * *}$ \\
Anxiety & Dependency & $.453^{* * *}$ \\
Personal goals & & $.604^{* * *}$ \\
Professional goals & & $-.62^{* * *}$ \\
Deviant behaviour & & $-.306^{* * *}$ \\
& Total score & .076 \\
& Violence & .066 \\
\hline
\end{tabular}

Note. $S D=$ standard deviation.

${ }^{*} \mathrm{p}<.05 .{ }^{* *} \mathrm{p}<.01 .{ }^{* * *} \mathrm{p}<.001$.

With regard to the links between social variables and the depressive symptoms score (Table 4), the students' opinion of the quality of their romantic relationship (concerning the absence of conflict and general satisfaction) was significantly and inversely associated with their depressive symptoms score. As with the quality of the romantic relationship, the self-reported quality of support from friends was significantly and inversely associated with the students' level of depressive symptoms. However, students who were involved in a relationship did not show fewer depressive symptoms than their single counterparts. Moreover, being in a relationship for a certain amount of time was not significantly linked to the level of depressive symptoms. 
Table 4.

Associations (Fisher's F and Pearson's r) between Social Variables and Depression Score

\begin{tabular}{llccc}
\hline \multirow{2}{*}{ Variable } & \multicolumn{1}{c}{ Modality } & Mean depression & & \\
& score $(S D)$ & Fisher's $F(\mathrm{ddl})$ & Pearson's $r$ \\
\hline Romantic status & In a relationship & $10.63(8.51)$ & $F(1,387)=0.098$ & NA \\
\multicolumn{1}{l}{ Time spent with partner } & $10.89(8.09)$ & & \\
Sexual attraction & Heterosexual & NA & NA & -.121 \\
& Homosexual & $10.17(8.05)$ & $F(2,385)=$ & NA \\
& Bisexual & $15.44(7.63)$ & & \\
Romantic relation & Total score & NA & NA & $-.235^{* * *}$ \\
& Absence of conflict & NA & NA & $-.211^{* * *}$ \\
& Satisfaction & NA & NA & $-.287^{* * *}$ \\
& Intimacy & NA & NA & -.079 \\
Support from friends & & NA & NA & $-.217^{* * *}$ \\
\hline
\end{tabular}

Note. $S D=$ standard deviation; $\mathrm{ddl}=$ degrees of freedom; NA = not applicable.

${ }^{*} \mathrm{p}<.05 .{ }^{* *} \mathrm{p}<.01 .{ }^{* * *} \mathrm{p}<.001$.

Sexual orientation was also significantly associated with the depressive symptoms score, with a greater number of depressive symptoms in those having indicated a homosexual or bisexual attraction.

Academic variables were significantly linked to depressive symptoms scores (Table 5). The more positively the students rated their academic performance, the lower their depressive symptoms scores. In the same way, the more they considered themselves adjusted to college, the more motivated they were about their studies, and the more attached they were to their college institution, the less they experienced depressive symptoms.

\section{Predictive Correlates of Depressive Symptoms in the First Year of College}

The second step of the data analyses consisted in determining the hierarchical order of the identified correlates in terms of predicting depressive symptoms. First, the absence of multicollinearity between the independent variables was verified using the variance inflation factor (VIF) index. Then, the set of variables that were significantly associated with depressive symptoms was introduced into an analysis model of multiple linear regressions with the depressive symptoms scores as the dependent variable. The presence of VIF indices greater than 4 was discovered between the variables of "encouragement of autonomy from the father" and "affection from the father" and their equivalents with regard to the mother. After verification, the correlations greater than .70 that existed between these variables were grouped together into the following two variables: "paternal practices" and "maternal practices." Both of these two variables had satisfactory internal consistency (Cronbach's a greater than .80 ). 
Table 5 .

Associations (Fisher's F and Pearson's r) between Academic Variables and Depression Score

\begin{tabular}{|c|c|c|c|c|}
\hline Variable & Modality & $\begin{array}{c}\text { Mean depression } \\
\text { score }(S D) \\
\end{array}$ & Fisher's $F(\mathrm{ddl})$ & Pearson's $r$ \\
\hline \multirow{3}{*}{$\begin{array}{l}\text { Academic perfor- } \\
\text { mance }\end{array}$} & Below average & $18.09(9.93)$ & \multirow{3}{*}{$\begin{array}{l}F(2,385)= \\
8.011^{* * *}\end{array}$} & \multirow{3}{*}{ NA } \\
\hline & Average & $12.27(8.65)$ & & \\
\hline & Above average & $9.82(7.11)$ & & \\
\hline \multirow[t]{5}{*}{ College adjustment } & Total score & NA & NA & $-.55^{* * * *}$ \\
\hline & Academic motivation & NA & NA & $-.355^{* * *}$ \\
\hline & Attachment to college & NA & NA & $-.337^{* * *}$ \\
\hline & Emotional adjustment & NA & NA & $-.519^{* * *}$ \\
\hline & Academic adjustment & NA & NA & $-.384^{* * *}$ \\
\hline
\end{tabular}

Note. $S D=$ standard deviation; $\mathrm{ddl}=$ degrees of freedom; $\mathrm{NA}=$ not applicable.

${ }^{*} \mathrm{p}<.05 .{ }^{* *} \mathrm{p}<.01 .{ }^{* * *} \mathrm{p}<.001$.

To control for the effect of the gender variable, a step-by-step analysis was carried out by introducing this variable first, followed by the other independent variables. Table 6 summarizes the step-by-step multiple linear regression models that were carried out.

The results suggest that gender (Model 1) played a significant role in explaining the variance of depressive symptoms within the sample. Once this variable had been controlled for, the introduction of the other 19 variables into the equation (Model 2) significantly improved the prediction of depressive symptoms. The analyses isolated eight variables that were uniquely associated with depressive symptoms in first-year college students. In decreasing order of importance (according to the value of the partial correlation index associated with each variable), these factors were: (1) the absence of personal goals (i.e., not knowing in which direction they were heading); (2) a high level of anxiety; (3) the presence of dysfunctional thoughts regarding success; (4) not feeling emotionally adjusted to college (i.e., having difficulty dealing with the stress of college life); (5) being female; (6) a lack of warmth and encouragement of autonomy from their mother, on the one hand; and (7) from their father, on the other hand; (8) being homosexual or bisexual. By taking these eight correlates into account, a major portion of the variance of the principal variable (depressive symptoms in these college students) was explained $\left(\mathrm{R}^{2}=.660\right.$; Variation in $\left.\mathrm{R}^{2}=.639\right)$. 
Table 6.

Sociodemographic, Academic, Social, Family-Related, and Personal Predictive Variables of Depression Score (Multiple Linear Regression Analyses, Models 1 and 2)

\begin{tabular}{|c|c|c|c|c|c|c|c|c|}
\hline & \multirow[b]{2}{*}{ Variable } & \multicolumn{2}{|c|}{$\begin{array}{c}\text { Unstandardized } \\
\text { coefficients }\end{array}$} & \multirow[b]{2}{*}{ B } & \multirow[b]{2}{*}{$\mathrm{T}$} & \multicolumn{2}{|c|}{$95 \% \mathrm{CI}$ for $\mathrm{A}$} & \multirow{2}{*}{$\begin{array}{l}\text { Part. } \\
\text { corr. }\end{array}$} \\
\hline & & $\mathrm{A}$ & $S E$ & & & $L L$ & $\mathrm{UL}$ & \\
\hline \multirow[t]{2}{*}{1} & (Constant) & 9.679 & 0.917 & & $10.55^{* * *}$ & 7.873 & 11.484 & \\
\hline & Gender & 2.595 & 1.136 & 0.146 & $2.285^{*}$ & 0.358 & 4.833 & .146 \\
\hline \multirow[t]{22}{*}{2} & (Constant) & $23 \cdot 398$ & 4.627 & & $5.057^{* * *}$ & 14.279 & 32.518 & \\
\hline & Gender & 2.471 & 0.825 & 0.139 & $2.993^{* *}$ & 0.844 & 4.098 & .119 \\
\hline & Age & -0.067 & 0.148 & -0.020 & -0.453 & -0.360 & 0.225 & -.018 \\
\hline & Romantic satisfaction & -0.024 & 0.134 & -0.010 & -0.181 & -0.288 & 0.239 & -.007 \\
\hline & Absence of romantic conflict & -0.084 & 0.185 & -0.025 & -0.453 & -0.449 & 0.281 & -.018 \\
\hline & Homo/bisexuality & 2.496 & 1.121 & 0.095 & $2.227^{*}$ & 0.287 & 4.705 & .088 \\
\hline & Support from friends & 0.000 & 0.090 & 0.000 & 0.002 & -0.177 & 0.177 & .000 \\
\hline & Academic motivation & -0.042 & 0.067 & -0.033 & -0.626 & -0.175 & 0.090 & -.025 \\
\hline & Attachment to college & -0.018 & 0.053 & -0.016 & -0.338 & -0.123 & 0.087 & -.013 \\
\hline & Emotional adjustment to college & -0.141 & 0.050 & -0.145 & $-2.817^{* *}$ & -0.239 & -0.042 & -.112 \\
\hline & Academic adjustment to college & -0.026 & 0.080 & -0.018 & -0.323 & -0.183 & 0.131 & -.013 \\
\hline & $\begin{array}{l}\text { Self-reported academic } \\
\text { performance }\end{array}$ & -0.580 & 0.661 & -0.042 & -0.877 & -1.883 & 0.724 & -.035 \\
\hline & Parental supervision & -0.023 & 0.140 & -0.009 & -0.172 & -0.210 & 0.187 & -.006 \\
\hline & Father (autonomy and warmth) & -0.832 & 0.357 & -0.105 & $-2.329^{*}$ & -1.535 & -0.128 & -.092 \\
\hline & Mother (autonomy and warmth) & -0.919 & 0.368 & -0.113 & $-2.498^{*}$ & -1.645 & -0.194 & -.099 \\
\hline & Family cohesion & 0.018 & 0.367 & 0.002 & 0.048 & -0.706 & 0.741 & .002 \\
\hline & Family conflict & -0.265 & 0.355 & -0.032 & -0.748 & -0.964 & 0.434 & -.030 \\
\hline & Professional goals & 0.051 & 0.067 & 0.037 & 0.760 & -0.081 & 0.184 & .030 \\
\hline & Personal goals & -0.258 & 0.049 & -0.335 & $-5.213^{* * *}$ & -0.355 & -0.160 & -.206 \\
\hline & Anxiety & 0.171 & 0.047 & 0.192 & $3.670^{* * *}$ & 0.079 & 0.263 & .145 \\
\hline & Dysfunctional thoughts/success & 0.333 & 0.091 & 0.190 & $3.661^{* * *}$ & 0.154 & 0.513 & .145 \\
\hline & $\begin{array}{l}\text { Dysfunctional thoughts/ } \\
\text { dependency }\end{array}$ & 0.010 & 0.089 & 0.006 & 0.110 & -0.166 & 0.186 & .004 \\
\hline
\end{tabular}

Note. $S E=$ Standard error; Part. corr. = partial correlation.

Model 1: $\mathrm{R}^{2}=.021 ; \mathrm{F}_{1,229}=5.222, \mathrm{p}=.023$

Model 2: $\mathrm{R}^{2}=.660$; Variation in $\mathrm{R}^{2}=.639$; variation in $\mathrm{F}_{22,217}=18.488, \mathrm{p}<.001$

${ }^{*} p<.05 .{ }^{* *} p<.01 .{ }^{* * *} p<.001$. 


\section{Discussion}

This study sought to identify and rank the personal, family-related, social, and academic correlates of depressive symptoms in first-year college students. More than $13 \%$ of the students in the research sample could be considered to have a moderate to severe level of depressive symptoms. This prevalence is in line with that shown by Eisenberg, Gollust, Golberstein, \& Hefner (2007), for example. Although this prevalence falls below that found in certain other studies (Ibrahim et al., 2013), it still confirms the need for researchers and practitioners to work toward understanding and providing care for these young people as they undergo this double transition from adolescence to adulthood and from one form of education to a new and different one.

This study confirmed, as have previous studies, that it is the combination and accumulation of a significant number of factors (personal, family-related, social, and academic) that influence depressive symptoms in emerging adulthood. There is no single cause for the depressive state (Patten \& Juby, 2008). Sociodemographic, family-related, academic, social, and personal variables were among those associated with depressive symptoms in this population of emerging young adults.

The correlate most strongly associated with depressive symptoms is the absence of personal goals. This result confirms the adaptive characteristic of self-projection into the future over the course of such transition periods as emerging adulthood (Stein, 2008). Furthermore, this study also confirmed the impact of anxiety (Boujut et al., 2009) and cognitive distortions (Alloy et al., 2006; Hallion \& Ruscio, 2011) on depressive symptoms in postsecondary students. In particular, it seems that dysfunctional thoughts concerning success, which engender a sense of pressure to perform, are detrimental to students' mental health (Zakari \& Bendahman, 2011).

Feeling unable to handle the academic, social, and emotional demands of postsecondary education can also have an impact on young people's mental health throughout the transition into adulthood (Land \& Legters, 2002; Pelkonen et al., 2008). Students who feel overwhelmed by the stress of arriving in a new institution, with all the adjustment that this entails, could very quickly feel insecure and in pain (Barnett, 2007; Schwartz et al., 2005).

The participants' gender was also revealed as one of the principal correlates associated with depressive symptoms (Klein et al., 2013). The female subjects in the sample exhibited more depressive symptoms than the male subjects, a tendency that has been widely mentioned in the literature (Ghodasara et al., 2011; Richards \& Salamanca Sanabria, 2014). The specific challenges faced by female youth, linked to expectations and emerging social roles (Nolen-Hoeksema \& Girgus, 1994), as well as the more or less subtle inequalities of gender relation models, may contribute to this preponderance of depressive symptoms among female youth (Zucker \& Landry, 2007). Moreover, they may think of problems as being more complex, attribute them more often to internal factors, and have a greater tendency to ruminate and co-ruminate rather than adopt active coping strategies (Nolen-Hoeksema, Larson, \& Grayson, 1999), thereby increasing their risk of depressive symptoms (Seiffge-Krenke \& Stemmler, 2002; White \& Shih, 2012). However, it should be noted that other studies have not found a higher risk of depressive symptoms among female college student samples, which suggests that emerging adulthood may be a period 
where the prevalence of depressive symptoms is similar in both genders (e.g., Ibrahim, Kelly, Challenor \& Glazebrook, 2010).

Family problems are not exempt from the model since a lack of warmth and encouragement of autonomy provided by both the mother and the father are among the major correlates associated with depressive symptoms (Kins et al., 2012). Furthermore, these family-related factors seem more preponderant than social factors (support from friends and romantic relationships), contrary to findings from other studies (Eberhart \& Hammen, 2006; Galambos et al., 2004). It seems that the family takes precedence over friends, even at this age, when it comes to preventing mental health problems.

Furthermore, the results of the present study confirmed a higher level of depressive symptoms in students who indicated being attracted to people of the same sex or of both sexes, probably linked in part to the discrimination that these individuals can suffer (Grant et al., 2013; Wichstrøm \& Hegna, 2003). This link might well have been even stronger if the measure had taken into account sexual experiences or bullying/teasing related to sexual orientation instead of sexual orientation alone (Lencl \& Matuga, 2010; Wichstrøm \& Hegna, 2003).

\section{Limitations and Future Directions}

Some limitations of this study must be mentioned. First, it should be noted that the tools used were abridged versions of validated, well-known instruments. The length of time required to complete the entire questionnaire could also limit the validity of the results. Furthermore, the selected methodology could not be used to unequivocally establish the anteriority of the identified risk correlates on depressive symptoms, which would have required prospective longitudinal data. Collecting the data at one single assessment time weakened the contribution in that the associated variables were not clearly risk factors or predictors but should be considered correlates of elevated levels of depressive symptoms. In addition, it would have been worthwhile to compare a sample of students from other years with our sample of first-year students to clarify which variables are associated specifically with depressive symptoms in students going through academic transition. Future studies will be necessary to further explore that aspect of postsecondary transition. Finally, a comparison with a clinical sample could have distinguished variables that were associated with clinical depression from those to be targeted with comprehensive or specific prevention.

Despite these limitations, this study has the advantage of being one of the only ones to identify the correlates that may help to explain the presence of depressive symptoms in Canadian first-year college students.

\section{Conclusion}

The results of this study open up new avenues for the prevention of, and fight against, depressive symptoms in first-year college students. By intervening in various target areas (personal, family-related, academic, and social), mental health professionals can provide support for the psychosocial adjustment of postsecondary students. In this regard, a program called Zenétudes has recently been established by a research team and could be a good tool to enhance mental health in students going through postsecondary transi- 
tion (Marcotte, Viel, Paré, \& Lamarre, 2015). This tri-level, multidimensional program includes both a large-group experience with a teacher and small-group interactions for selected vulnerable students led by mental health professionals.

Difficulties experienced over emerging adulthood may result in vulnerabilities lasting a lifetime. Indeed, the results of studies on the subject suggest a very high level of risk for recurrence of depressive symptoms when left unresolved in adolescence and early adulthood (Hammen, Brennan, Keenan-Miller, \& Herr, 2008; Lewinsohn, Rohde, Klein, \& Seeley, 1999). According to some authors, however, this period of life also offers a unique window of opportunity (Masten et al., 2004). After all, is the transition to adulthood not the period for forming one's identity and the "the age of all possibilities" (Arnett, 2000, p. 189), and therefore a particularly crucial period for managing depressive symptoms?

\section{References}

Allen, G. M. (2004). Bats: biology, behavior, and folklore. Mineola, NY: Dover Publications.

Alloy, L. B., Abramson, L. Y., Whitehouse, W. G., Hogan, M. E., Panzarella, C., \& Rose, D. T. (2006). Prospective incidence of first onsets and recurrences of depression in individuals at high and low cognitive risk for depression. Journal of Abnormal Psychology, 115(1), 145-156.

American College Health Association. (2013). American College Health AssociationNational College Health Assessment II: Canadian reference group executive summary spring 2013. Hanover, MD: Author.

Arnett, J. J. (2000). Emerging adulthood: A theory of development from the late teens through the twenties. American Psychology, 55(5), 469-480.

Baker, R. W., \& Siryk, B. (1986). Exploratory intervention with a scale measuring adjustment to college. Journal of Counseling Psychology, 33(1), 31-39.

Barnett, R. (2007). A will to learn: Being a student in an age of uncertainty. Maidenhead, England: Society for Research into Higher Education \& Open University Press.

Beck, A. T., Epstein, N., Brown, G., \& Steer, R. A. (1988). An inventory for measuring clinical anxiety: Psychometric properties. Journal of Consulting and Clinical Psychology, 56(6), 893-901.

Beck, A. T., Steer, R. A., \& Brown, G. K. (1996). Manual for the Beck Depression Inventory-II. San Antonio, TX: Psychological Corporation.

Beiter, R., Nash, R., McCrady, M., Rhoades, D., Linscomb, M., Clarahan, M. et al. (2015). The prevalence and correlates of depression, anxiety and stress in a sample of college students. Journal of Affective Disorders, 173(1), 90-96.

Benton, S. A., Robertson, J. M., Tseng, W.-C., Newton, F. B., \& Benton, S. L. (2003). Changes in counseling center client problems across 13 years. Professional Psychology: Research and Practice, 34(1), 66-73. 
Boujut, E., Koleck, M., Bruchon-Schweitzer, M., \& Bourgeois, M. L. (2009). La santé mentale chez les étudiants : suivi d'une cohorte en première année d'université [Mental health among students: follow-up of a cohort during the first year of university]. Annales Médico-psychologiques, revue psychiatrique, 167(9), 662-668.

Bouteyre, E., Maurel, M., \& Bernaud, J.-L. (2007). Daily hassles and depressive symptoms among first year psychology students in France: The role of coping and social support. Stress \& Health, 23(2), 93-99.

Buhrmester, D., \& Furman, W. (1987). The development of companionship and intimacy. Child Development, 58, 1101-1113.

Choi, W., Patten, C., Christian Gillin, J., Kaplan, R., \& Pierce, J. (1997). Cigarette smoking predicts development of depressive symptoms among U.S. adolescents. Annals of Behavioral Medicine, 19(1), 42-50.

Daddona, M. F. (2011). Peer educators responding to students with mental health issues. New Directions for Student Services, 133, 29-39.

Duncan, B., \& Rees, D. I. (2005). Effect of smoking on depressive symptomatology: A reexamination of data from the national longitudinal study of adolescent health. American Journal of Epidemiology, 162(5), 461-470.

Eberhart, N. K., \& Hammen, C. L. (2006). Interpersonal predictors of onset of depression during the transition to adulthood. Personal Relationships, 13(2), 195-206.

Eisenbarth, C. (2012). Does self-esteem moderate the relations among perceived stress, coping, and depression? College Student Journal, 46(1), 149-157.

Eisenberg, D., Gollust, S. E., Golberstein, E., \& Hefner, J. L. (2007). Prevalence and correlates of depression, anxiety, and suicidality among university students. American Journal of Orthopsychiatry, 77(4), 534-542.

Fergusson, D. M., Boden, J. M., \& Horwood, L. J. (2009). Tests of causal links between alcohol abuse or dependence and major depression. Archives of General Psychiatry, 66(3), 260-266.

Fier, S. M., \& Brzezinski, L. G. (2010). Facilitating the high school to college transition for students with psychiatric disabilities: Information and strategies for school counselors. Journal of School Counseling, 8(10), 280-287.

Fletcher, J. M. (2009). Childhood mistreatment and adolescent and young adult depression. Social Science \& Medicine, 68(5), 799-806.

Freeston, M. H., Ladouceur, R., Rhéaume, J., Letarte, H., Gagnon, F., \& Thibodeau, N. (1994). Self-report of obsessions and worry. Behaviour Research and Therapy, 32(1), 29-36.

Frye, A. A., \& Liem, J. H. (2011). Diverse patterns in the development of depressive symptoms among emerging adults. Journal of Adolescent Research, 26(5), 570-590.

Galambos, N., Leadbeater, B., \& Barker, E. (2004). Gender differences in and risk factors for depression in adolescence: A 4-year longitudinal study. International Journal of Behavioral Development, 28(1), 16-25. 
Galambos, N. L., Barker, E. T., \& Krahn, H. J. (2006). Depression, self-esteem, and anger in emerging adulthood: Seven-year trajectories. Developmental Psychology, 42(2), $350-365$.

Geisner, I. M., Mallett, K., \& Kilmer, J. R. (2012). An examination of depressive symptoms and drinking patterns in first year college students. Issues in Mental Health Nursing, 33(5), 280-287.

Ghodasara, S. L., Davidson, M. A., Reich, M. S., Savoie, C. V., \& Rodgers, S. M. (2011). Assessing student mental health at the Vanderbilt University School of Medicine. Academic Medicine, 86(1), 116-121.

Gonzalez, O., Berry, J. T., McKnight-Eily, L. R., Strine, T., Edwards, V. J., Lu, H., \& Croft, J. B. (2010). Current depression among adults-United States, 2006 and 2008. MMWR (Morbidity and Mortality Weekly Report), 59(38), 1229-1235.

Gore, S., \& Aseltine, R. H. (2003). Race and ethnic differences in depressed mood following the transition from high school. Journal of Health and Social Behavior, 44(3), $370-382$.

Gourion, D., Arseneault, L., Vitaro, F., Brezo, J., Turecki, G., \& Tremblay, R. E. (2008). Early environment and major depression in young adults: A longitudinal study. Psychiatry Research, 161(2), 170-176.

Grant, J. E., Odlaug, B. L., Derbyshire, K., Schreiber, L. R. N., Lust, K., \& Christenson, G. (2013). Mental health and clinical correlates in lesbian, gay, bisexual, and queer young adults. Journal of American College Health, 62(1), 75-78.

Hallion, L. S., \& Ruscio, A. M. (2011). A meta-analysis of the effect of cognitive bias modification on anxiety and depression. Psychological Bulletin, 137(6), 940-958.

Hammen, C., Brennan, P. A., Keenan $\square$ Miller, D., \& Herr, N. R. (2008). Early onset recurrent subtype of adolescent depression: Clinical and psychosocial correlates. Journal of Child Psychology and Psychiatry, 49(4), 433-440.

Hazel, N. A., Hammen, C., Brennan, P. A., \& Najman, J. (2008). Early childhood adversity and adolescent depression: The mediating role of continued stress. Psychological Medicine, 38(04), 581-589.

Holland, J. J., Gottfredson, D. C., \& Power, P. G. (1980). Some diagnostic scales for research in decision making and personality: Identity, information, and barriers. Journal of Personality and Social Psychology, 39(6), 1191-1200.

Ibrahim, A. K., Kelly, S. J., Adams, C. E., \& Glazebrook, C. (2013). A systematic review of studies of depression prevalence in university students. Journal of Psychiatric Research, 47(3), 391-400.

Ibrahim, A. K., Kelly, S., Challenor, C., \& Glazebrook, C. (2010). Establishing the reliability and validity of the Zagazig Depression Scale in a UK student population: An online pilot study. BMC Psychiatry, 1O(107). doi:10.1186/1471-244X-10-107

Ibrahim, A. K., Kelly, S. J., \& Glazebrook, C. (2012). Reliability of a shortened version of the Zagazig Depression Scale and prevalence of depression in an Egyptian university student sample. Comprehensive Psychiatry, 53(5), 638-647. 
Imhasly, P. (2008). La santé en Suisse : Rapport national sur la santé 2008 [Health in Switzerland: National Report on Health 2008]. Genève, Suisse: Observatoire suisse de la santé.

Jeon, H. J. (2011). Depression and suicide. Journal of Korean Medical Association, 54(4), 370-375.

Kerr, D. L., Santurri, L., \& Peters, P. (2013). A comparison of lesbian, bisexual, and heterosexual college undergraduate women on selected mental health issues. Journal of American College Health, 61(4), 185-194.

Kerr, M., \& Stattin, H. (2000). What parents know, how they know it, and several forms of adolescent adjustment: Further support for a reinterpretation of monitoring. Developmental Psychology, 36, 366-380.

Kim, M., Han, H.-R., Hill, M., Rose, L., \& Roary, M. (2003). Depression, substance use, adherence behaviors, and blood pressure in urban hypertensive black men. Annals of Behavioral Medicine, 26(1), 24-31.

Kins, E., Soenens, B., \& Beyers, W. (2012). Parental psychological control and dysfunctional separation-individuation: A tale of two different dynamics. Journal of Adolescence, 35(5), 1099-1109.

Kitzrow, M. (2003). The mental health needs of today's college students: Challenges and recommendations. NASPA Journal, 41(1), 165-179.

Klein, D. N., Glenn, C. R., Kosty, D. B., Seeley, J. R., Rohde, P., \& Lewinsohn, P. M. (2013). Predictors of first lifetime onset of major depressive disorder in young adulthood. Journal of Abnormal Psychology, 122(1), 1-12.

Koc, M. (2011). Internet addiction and psychopathology. TOJET (Turkish Online Journal of Educational Technology), 1O(1), 143-148.

Land, D., \& Legters, N. (2002). The extent and consequences of risk in U.S. education. Yearbook of the National Society for the Study of Education, 101(2), 1-28.

LeBlanc, M. (1994). Questionnaire de la délinquance auto-révélée [Self-Reported Delinquency Scale]. Unpublished manuscript, Université de Montréal, Montréal, QC.

Lencl, M., \& Matuga, J. (2010). The lifetime bully: Investigating the relationship between adolescent bullying and depression in early adulthood. Journal of School Counseling, 8(7), 123-136.

Lewinsohn, P. M., Rohde, P., Klein, D. N., \& Seeley, J. R. (1999). Natural course of adolescent major depressive disorder: Continuity into young adulthood. Journal of the American Academy of Child \& Adolescent Psychiatry, 38(1), 56-63.

Locatelli, S. M., Kluwe, K., \& Bryant, F. B. (2012). Facebook use and the tendency to ruminate among college students: Testing mediational hypotheses. Journal of Educational Computing Research, 46(4), 377-394.

MacKean, G. (2011, June). Mental health and well-being in post-secondary education settings. CACUSS preconference workshop on mental health. 
Mackinnon, S. P., Sherry, S. B., Pratt, M. W., \& Smith, M. M. (2014). Perfectionism, friendship intimacy, and depressive affect in transitioning university students: A longitudinal study using mixed methods. Canadian Journal of Behavioural Science/ Revue canadienne des sciences du comportement, 46(1), 49-61.

Marcotte, D. (Ed.). (2013). La dépression chez les adolescents: État des connaissances, famille, école et stratégies d'intervention [Depression in Adolescents: State of Knowledge, Family, School and Intervention Strategies]. Montréal, QC: PUQ.

Marcotte, D., Viel, C., Paré, M. L., \& Lamarre, C. (2015, May). Development of a prevention program for first year college students presenting depressive or anxiety symptoms. Poster presented at the meeting of American College Health Association, Orlando, FL.

Marcotte, G., Marcotte, D., \& Bouffard, T. (2002). The influence of familial support and dysfunctional attitudes on depression and delinquency in an adolescent population. European Journal of Psychology of Education, 17(4), 363-376.

Marmorstein, N. R., Iacono, W. G., \& McGue, M. (2012). Associations between substance use disorders and major depression in parents and late adolescent-emerging adult offspring: An adoption study. Addiction, 107(11), 1965-1973.

Masten, A. S., Burt, K. B., Roisman, G. I., Obradovic, J., Long, J. D., \& Tellegen, A. (2004). Resources and resilience in the transition to adulthood: Continuity and change. Development and Psychopathology, 16(04), 1071-1094.

Miranda, R., Polanco-Roman, L., Tsypes, A., \& Valderrama, J. (2013). Perceived discrimination, ruminative subtypes, and risk for depressive symptoms in emerging adulthood. Cultural Diversity and Ethnic Minority Psychology, 19(4), 395-403.

Moos, R. H., \& Moos, B. S. (1994). Family Environment Scale manual: Development, Applications, Research (3rd ed.). Palo Alto, CA: Consulting Psychologists Press.

Morris, B., McGrath, A., Goldman, M., \& Rottenberg, J. (2014). Parental depression confers greater prospective depression risk to females than males in emerging adulthood. Child Psychiatry \& Human Development, 45(1), 78-89.

Needham, B. L. (2008). Reciprocal relationships between symptoms of depression and parental support during the transition from adolescence to young adulthood. Journal of Youth and Adolescence, 37(8), 893-905.

Nolen-Hoeksema, S., \& Girgus, J. S. (1994). The emergence of gender differences in depression during adolescence. Psychological Bulletin, 115(3), 424-431.

Nolen-Hoeksema, S., Larson, J., \& Grayson, C. (1999). Explaining the gender difference in depressive symptoms. Journal of Personality and Social Psychology, 77(5), 1061-1074.

O’Hara, R. E., Armeli, S., Boynton, M. H., \& Tennen, H. (2014). Emotional stressreactivity and positive affect among college students: The role of depression history. Emotion, 14(1), 193-210. 
Otis, J., Ryan, B., \& Chouinard, N. (1999). Impact du "Projet 10" sur le mieux-être sexuel de jeunes gais et bisexuels [Impact of «Project 10» on the sexual well-being of gay and bisexual youth]. Montréal, QC: Régie régionale de la Santé et des Services sociaux Montréal Centre.

Park, A. L., Fuhrer, R., \& Quesnel-Vallée, A. (2013). Parents' education and the risk of major depression in early adulthood. Social Psychiatry and Psychiatric Epidemiology, 48(11), 1829-1839.

Patten, S., \& Juby, H. (2008). A profile of clinical depression in Canada. Unpublished manuscript, University of Calgary, Calgary, AB.

Peden, A. R., Rayens, M. K., Hall, L. A., \& Beebe, L. H. (2001). Preventing depression in high-risk college women: A report of an 18-month follow-up. Journal of American College Health, 49(6), 299-306.

Pelkonen, M., Marttunen, M., \& Aro, H. (2003). Risk for depression: A 6-year followup of Finnish adolescents. Journal of Affective Disorders, 77, 41-51.

Pelkonen, M., Marttunen, M., Kaprio, J., Huurre, T., \& Aro, H. (2008). Adolescent risk factors for episodic and persistent depression in adulthood: A 16-year prospective follow-up study of adolescents. Journal of Affective Disorders, 106(1-2), 123-131.

Pettit, J. W., Roberts, R. E., Lewinsohn, P. M., Seeley, J. R., \& Yaroslavsky, I. (2011). Developmental relations between perceived social support and depressive symptoms through emerging adulthood: Blood is thicker than water. Journal of Family Psychology, 25(1), 127-136.

Pirbaglou, M., Cribbie, R., Irvine, J., Radhu, N., Vora, K., \& Ritvo, P. (2013). Perfectionism, anxiety, and depressive distress: Evidence for the mediating role of negative automatic thoughts and anxiety sensitivity. Journal of American College Health, 61(8), 477-483.

Power, M., Katz, R., McGuffin, P., Duggan, C., Lam, D., \& Beck, A. (1994). The Dysfunctional Attitude Scale (DAS): A comparison of forms A and B and proposals for a new subscaled version. Journal of Research in Personality, 28(3), 263-276.

Procidano, M., \& Heller, K. (1983). Measures of perceived social support from friends and from family: Three validation studies. American Journal of Community Psychology, 11(1), 1-24.

Reinherz, H. Z., Giaconia, R. M., Carmola Hauf, A. M., Wasserman, M. S., \& Silverman, A. B. (1999). Major depression in the transition to adulthood: Risks and impairments. Journal of Abnormal Psychology, 108(3), 500-510.

Richards, D., \& Salamanca Sanabria, A. (2014). Point-prevalence of depression and associated risk factors. The Journal of Psychology, 148(3), 305-326.

Rizzo, C., Daley, S., \& Gunderson, B. (2006). Interpersonal sensitivity, romantic stress, and the prediction of depression: A study of inner-city, minority adolescent girls. Journal of Youth and Adolescence, 35(3), 444-453.

Robbins, R. (1994). An assessment of perceptions of parental autonomy support and control: Child and parent correlates (Unpublished doctoral dissertation). University of Rochester, Rochester, NY. 
Robbins, S. B., Payne, E. C., \& Chartrand, J. M. (1990). Goal instability and later life adjustment. Psychology and Aging, 5(3), 447-459.

Rosal, M. C., Ockene, I. S., Ockene, J. K., Barrett, S. V., Ma, Y., \& Hebert, J. R. (1997). A longitudinal study of students' depression at one medical school. Academic Medicine, $72(6), 542-546$.

Rosenthal, B., \& Wilson, W. C. (2008). Mental health services: Use and disparity among diverse college students. Journal of American College Health, 57(1), 61-68.

Schwartz, S. J., Côté, J. E., \& Arnett, J. J. (2005). Identity and agency in emerging adulthood: Two developmental routes in the individualization process. Youth \& Society, 37(2), 201-229.

Seiffge-Krenke, I., \& Stemmler, M. (2002). Factors contributing to gender differences in depressive symptoms: A test of three developmental models. Journal of Youth and Adolescence, 31(6), 405-417.

Smith, D. J., \& Blackwood, D. H. (2004). Depression in young adults. Advances in Psychiatric Treatment, 1O(1), 4-12.

Statistics Canada. (2008). National Longitudinal Survey of Children and Youth. Cycle 7. Ottawa: Canada.

Stein, M. (2008). Transitions from care to adulthood: Messages from research for policy and practice. In M. Stein \& E. R. Munro (Eds.), Young people's transitions from care to adulthood: International research and practice (pp. 289-306). London, UK: Jessica Kingsley.

Storrie, K., Ahern, K., \& Tuckett, A. (2010). A systematic review: Students with mental health problems - a growing problem. International Journal of Nursing Practice, 16(1), 1-6.

White, M., \& Shih, J. (2012). A daily diary study of co-rumination, stressful life events, and depressed mood in late adolescents. Journal of Clinical Child and Adolescent Psychology, 41(5), 598-610.

Whitton, S. W., \& Kuryluk, A. D. (2012). Relationship satisfaction and depressive symptoms in emerging adults: Cross-sectional associations and moderating effects of relationship characteristics. Journal of Family Psychology, 26(2), 226-242.

Whitton, S. W., Weitbrecht, E. M., Kuryluk, A. D., \& Bruner, M. R. (2013). Committed dating relationships and mental health among college students. Journal of American College Health, 61(3), 176-183.

Wichstrøm, L., \& Hegna, K. (2003). Sexual orientation and suicide attempt: A longitudinal study of the general Norwegian adolescent population. Journal of Abnormal Psychology, 112(1), 144-151.

Wickrama, K. A., Wickrama, T., \& Lott, R. (2009). Heterogeneity in youth depressive symptom trajectories: Social stratification and implications for young adult physical health. Journal of Adolescent Health, 45(4), 335-343.

Young, J. F., Berenson, K., Cohen, P., \& Garcia, J. (2005). The role of parent and peer support in predicting adolescent depression: A longitudinal community study. Journal of Research on Adolescence, 15(4), 407-423. 
Zakari, S., \& Bendahman, H. (2011). Syndrome d'épuisement scolaire et dépression à l'adolescence: Étude qualitative auprès d'une vingtaine de lycéens français [Academic Burnout and depression in adolescence: Qualitative study among about 20 French high school students]. Les Collectifs du Cirp, 2, 318-329.

Zucker, A. N., \& Landry, L. J. (2007). Embodied discrimination: The relation of sexism and distress to women's drinking and smoking behaviors. Sex Roles, 56(3-4), 193-203.

\section{Contact Information}

Aude Villatte

Université du Québec en Outaouais

Département de Psychologie et de Psychoéducation

aude.villatte@uqo.ca

Aude Villatte is a professor-researcher in the Department of Psychology and Psychoeducation at Université du Québec en Outaouais (Canada). She specializes in the areas of academic and emotional adjustment of secondary and postsecondary students.

Diane Marcotte is a professor-researcher in the Department of Psychology at Universite du Québec à Montréal (Canada). Author of a depression prevention program for teenagers (Pare-chocs) and a depression and anxiety prevention program for young adults (Zenétudes), she is interested in the emergence of depression and anxiety during the transition from primary to secondary school and from high school to college.

Alexandra Potvin is a professor of social work at Cégep de Saint Jérôme (Canada). She worked for 12 years with at-risk youth (in secondary schools and Child Protection Services). 